\title{
DOES THE TYPE OF NEONATAL UNIT INFLUENCE THE BIRTH WEIGHT AND GESTATIONAL AGE OF LATE PRETERM INFANTS ADMITTED TO POST NATAL WARD AFTER BIRTH?
}

\author{
P. Arora ${ }^{1}$, R. Price ${ }^{1}$, P. Fleming ${ }^{1,2}$, N. Aladangady ${ }^{1,3}$
}

${ }^{I}$ Neonates, Homerton University Hospital, ${ }^{2}$ Barts and The London Children's Hospital, Royal London Hospital, ${ }^{3}$ Barts and The London School of Medicine and Dentistry, Queen Mary College, London, UK

Background: Infants born at $34^{+0}$ through $36^{+6}$ weeks gestation have been defined as 'late preterm' infants ${ }^{1}$. It is not clear whether these babies can be managed on the post natal ward or routinely need to be admitted to the neonatal unit after birth.

Aim: To conduct national survey of admission practice for late preterm infants directly to Postnatal Ward (PNW) after birth.

Method: A structured telephone survey of all neonatal units in England.

Results: Out of the 184 neonatal units 180 responded (98\%). Of the 4 non responders 2 were from Level 1 , and one each from Level 2 and Level 3 units. The details of neonatal units, gestational age (GA) \& B Wt limit for direct PNW admission after birth are presented in table 1 . Significantly lower gestational age infants were admitted directly to PNW in level 2 units compared to Level 1 (p 0.03; CI 0.03-0.52) and Level 3 units compared to Level 2 (p 0.02; CI 0.028-0.211). Mean B Wt limit for direct PNW admission was significantly lower in Level 3 units compared to Level 1 (p 0.011; CI 0.028-0.211).

\begin{tabular}{|l|l|l|l|l||}
\hline $\begin{array}{l}\text { Type of Neonatal } \\
\text { Unit }\end{array}$ & Number responded & $\begin{array}{l}\text { Mean GA limit for } \\
\text { direct PNW } \\
\text { admission (SD) }\end{array}$ & $\begin{array}{l}\text { Mean B Wt limit for } \\
\text { direct PNW } \\
\text { admission (SD) }\end{array}$ & $\begin{array}{l}\text { Nursery nurse } \\
\text { present }\end{array}$ \\
\hline Level 1 & 49 & $35.19(0.7)$ wks & $1.99(0.23) \mathrm{kg}$ & $17(35 \%)$ \\
\hline Level 2 & 84 & $34.91(0.67) \mathrm{wks}$ & $1.94(0.20) \mathrm{kg}$ & $32(38 \%)$ \\
\hline Level 3 & 47 & $34.61(0.7) \mathrm{wks}$ & $1.87(0.18) \mathrm{kg}$ & $23(48 \%)$ \\
\hline
\end{tabular}

[Table1: Gestational age \& B Wt limit for direct PN]

Conclusion: Type of neonatal unit influences the lower limit of B Wt and gestational age of late preterm infants admitted directly to PNW after birth.

Reference: 1)Engle et al. Pediatrics 2007. 